\title{
DESENVOLVIMENTO DE UM SISTEMA DE TELEMETRIA PARA MONITORAMENTO TÉRMICO EM CASAS DE VEGETAÇÃO
}

\author{
R. Z. Barbosa' ${ }^{1}$ e J. E. M. Perea Martins ${ }^{2}$ \\ ${ }^{1}$ Faculdade de Ciências Agronômicas, UNESP - Univ Estadual Paulista, Campus de, \\ Botucatu, SP, Brasil. \\ ${ }^{2}$ Faculdade de Ciências, Departamento de Computação, UNESP - Univ Estadual Paulista, \\ Campus de Bauru, SP, Brasil.
}

\section{RESUMO}

Este artigo apresenta o desenvolvimento de um sistema de telemetria aplicado no monitoramento de temperatura em casas de vegetação, o qual inclui aspectos de hardware e software. As informações são transmitidas por rádio a um computador que possui um software, especialmente desenvolvido neste trabalho, para receber as informações, e armazená-las num arquivo no formato de texto, sendo que as mesmas podem ser processadas com outros programas aplicativos. O hardware de telemetria foi baseado em um módulo de rádio comunicação, que tem um pino de configuração que permite sua configuração direta como transmissão ou recepção de dados, facilitando o projeto de hardware. Os resultados mostraram um alcance de 120 metros, sem erros de transmissão. O sistema de telemetria desenvolvido pode ser conectado a qualquer dispositivo de sensoriamento que tenha uma saída de comunicação no padrão serial RS-232, que é muito comum em instrumentos de medições e, portanto, o também pode ser aplicado no monitoramento de diversos outros parâmetros físicos na área agrícola e ambiental.

Palavras-chave: Monitoramento térmico, Aquisição de dados, Telemetria.

\section{DEVELOPMENT OF A TELEMETRY SYSTEM FOR THERMAL MONITORING IN GREENHOUSE}

\begin{abstract}
This paper shows the design of a telemetry system used for greenhouse temperature monitoring, which includes hardware and software aspects. The temperature data is transmitted by radio to a computer that has software specially designed in this work, which performs the data reception and storage into a the text file format that enables the later data processing for other software as text editors or spreadsheets. The telemetry hardware was based on a radio communication module that has a specific pin to configure it as transmitter or receiver, what make easier the hardware design. The results show a radio transmission range at 120 meters, without errors. The telemetry system developed can be connected to any sensing device that has a serial communication interface with RS-232 standard, which is common in commercial measuring instruments and enable the system usage for other physical parameters measurement in the agricultural and environmental areas.
\end{abstract}

Keywords: Temperature monitoring, Data acquisition, Telemetry.

\footnotetext{
${ }^{1}$ rogerio@fca.unesp.br
} 


\section{INTRODUÇÃO}

O monitoramento climático em sistemas agrícolas exerce grande importância no processo produtivo, dentre as variáveis mensuradas a temperatura do ar é uma das mais importantes, influenciando diretamente em fatores como incidência pragas e doenças, estimativas de safras (ARAÚJO et al., 2014), evapotranspiração da cultura, etc. (GOMES et al., 2014; BACK, 2008), sendo que nesse contexto o uso das tecnologias computacionais favorece a aquisição e gerenciamento de informações referentes ao monitoramento da temperatura do clima em geral (CLEAVER \& GANGULY, 2005; WEBSTER, 1999) permitindo que essas informações possam ser utilizadas como uma base sólida para a tomada de decisões. Deste modo, uma das tecnologias que mais se destacam no setor agrícola é a de transmissão de dados sem fio, através de sistemas de rádio, conhecida como telemetria (ALMARAZ et al., 2014), a qual, além da medição a distância, também dá mobilidade ao sistema de medição, permitindo a instalação de sensores em diversos pontos dentro de um raio específico de alcance, o que favorece a sua utilização em propriedades rurais (CARDEN et al., 2002). É importante ressaltar que atualmente grande parte dos sistemas sem fio aplicados a agricultura operam com transmissão na ordem de apenas algumas dezenas de metros podendo variar de 50 a 500 metros já possuindo aplicabilidade real.

Armindo et al. (2011) desenvolveram um sistema que utilizava a transferência de dados sem fio, no entanto, em seu trabalho, não apresentou dados referentes ao alcance de transmissão do sinal de rádio, que é importante para a validação do sistema. No entanto, os autores aplicaram o sistema na medição da vazão em dutos de água, pois constataram que havia poucos estudos nesta área, o que demonstra a aplicabilidade da telemetria. Neste mesmo sentido Ferrasa (2008) realizou um trabalho buscando o monitoramento da temperatura do ar em silos graneleiros por meio de sistemas de rádio. Em seu estudo, utilizou transmissores e receptores com frequência de 433,9 $\mathrm{MHz}$ com monitoramento em tempo real, dados originários de 16 sensores, numa distância variando de 1 a 30 metros. O sistema operou sem erros em uma distância de até 15 metros, sendo que em 30 metros a quantidade de erros durante a transmissão foi de $35 \%$. O ideal é uma taxa de erros nula, para evitar problemas com os dados mensurados.

A análise dos dados em tempo real coletados na área agrícola, bem como a facilidade da aquisição destes dados, mesmo em locais de difícil acesso são as principais vantagens do monitoramento sem fio. Neste sentido Majone et al. (2013) desenvolveram uma rede que monitora a umidade e a temperatura do solo numa plantação de maçãs numa área com alta declividade e difícil acesso, numa região montanhosa. Sensores de temperatura do solo foram instalados numa profundidade de $20 \mathrm{~cm}$ que coletavam os dados em tempo real e enviados para um computador central. Observou que a empregabilidade de sistemas de monitoramento sem fio facilita muito a coleta dos dados de forma simples e detalhada. No entanto, neste estudo observou-se que os instrumentos de medição, principalmente os sensores, precisam ser calibrados com atenção e critério para garantir a segurança e a confiabilidade na coleta das informações a campo.

Neste mesmo sentido Casas et al. (2014) desenvolveram e implementaram um sistema para monitoramento térmico em processos de compostagem incluindo sistema de hardware e software. Constatou que o sistema desenvolvido facilitou $o$ gerenciamento e controle do processo de compostagem de resíduos vegetais. Visto que o monitoramento térmico tem grande influência da compostagem, isso devido a forma na qual as bactérias degradam o material a ser decomposto.

Trabalhos utilizando tecnologias de monitoramento sem fio é cada vez mais 
frequente na agricultura moderna, a exemplo Zhang et al. (2013) utilizaram uma rede de sensores sem fio no monitoramento da umidade do solo no cultivo do milho, no total foram distribuídos 18 nós de sensores em duas áreas de estudo avaliando a variabilidade espacial da umidade do solo em cada área. Neste estudo a primeira área obteve uma variação da umidade do solo de $6,5 \%$ e na segunda área obteve uma variação da umidade de $12,5 \%$, ou seja, constatou-se que mesmo em áreas vizinhas o solo, em muitas vezes, é heterogêneo, e que irrigando uma área como a do estudo de maneira proporcional pode economizar até $12,5 \%$ de água na irrigação.

Este trabalho tem como diferencial a utilização de uma tecnologia de fácil utilização e de baixo custo, características essas que promove uma maior aceitação por parte do usuário final. Atualmente, existem várias tecnologias voltadas a transferência de dados sem fio existentes no mercado. Dentre elas as que mais se destacam é a tecnologia de módulos de 433 $\mathrm{MHz}$ da Radiometrix e o ZigBee. A grande

\section{MATERIAL E MÉTODOS}

O trabalho foi realizado em uma casa de vegetação localizada no campus da Faculdade de Ciências da UNESP, na cidade de Bauru - SP, cujas coordenadas geográficas $22^{\circ} 20^{\prime} 40^{\prime \prime}$ de latitude sul e $49^{\circ} 1^{\prime} 51^{\prime \prime}$ de longitude oeste e 526 metros de altitude. A casa de vegetação em estudo foi do tipo capela com 6 metros de largura e 10 metros de comprimento e pé-direito de 3 metros. A estrutura foi construída com metal galvanizado instalada sobre um piso em alvenaria.

Neste trabalho, o circuito de hardware de telemetria foi baseado no dispositivo de rádio transceptor modelo BIM2-433-160 da Radiometrix, o qual pode ser configurado para operar como transmissor ou receptor, através de um simples pino específico de controle. $\mathrm{O}$ BIM2-433-160 opera tensão de $5 \mathrm{~V}$. Quando operando como transmissor, o seu consumo médio de corrente de 17,5 mA, e vantagem da utilização de módulos de 433 MHz é a facilidade do uso em comparação a tecnologia ZigBee, pois não é necessário uma programação prévia do módulo, outra característica importante deste módulo é sua performance, pois dificilmente ocorre erros durante a transmissão de dados (BAGSHAW et al., 2014). Em contra partida, os módulos ZigBee possuem um protocolo de comunicação em rede, isto é, permite a utilização de vários dispositivos sem que haja colisão de dados. Todas as características citadas acima nos levou a escolher para o presente estudo módulos de $433 \mathrm{MHz}$ da Radiometrix, que além destas vantagens possuem um baixo consumo de energia $(20 \mathrm{~mA})$ e um alto grau de confiança.

Esse artigo, apresenta nas próximas seções uma descrição da metodologia de trabalho e uma análise do sistema implementado, onde os testes incluíram a análise do alcance dos módulos de rádio e taxa e tratamento de erros durante o processo de comunicação, utilizando diferentes taxas de transmissão de dados.

quando operando como receptor, o consumo de corrente é de $28,0 \mathrm{~mA}$.

$\mathrm{O}$ módulo de rádio, que consiste basicamente no dispositivo de rádio e o conversor TTL/RS-232, recebe os dados no formato serial, onde cada bit de informação é enviado serialmente pelo transmissor até o receptor que envia estas informações a um software que recebe e trata estes dados. Assim, o mesmo pode ser conectado a qualquer dispositivo de sensoriamento que tenha saída serial de dados, o que é muito comum de se encontrar em modelos comerciais.

O módulo receptor envia os dados a um computador, onde os mesmos devem ser processados. Assim, no computador deve haver um software específico para esse fim. No presente trabalho, o software recebia em tempo real as informações de temperatura do ar, originárias do sensor, via rádio. Neste trabalho, um módulo 
configurado como transmissor foi acoplado, através da porta de comunicação serial, a um termo-higrômetro modelo HTR-152, o que operava com taxa de amostragem de 0,8 segundos, consumo de energia de 8,5 $\mathrm{mA}$, resolução de $0,1{ }^{\circ} \mathrm{C}$ para temperatura do ar.
A Figura 1 ilustra o esquema de montagem dos módulos de rádio transmissão e de recepção de dados, sendo que o computador foi colocado na parte externa da casa de vegetação para recepção e processamento das informações. É valido lembrar que ambos os módulos utilizam o mesmo modelo de rádio.

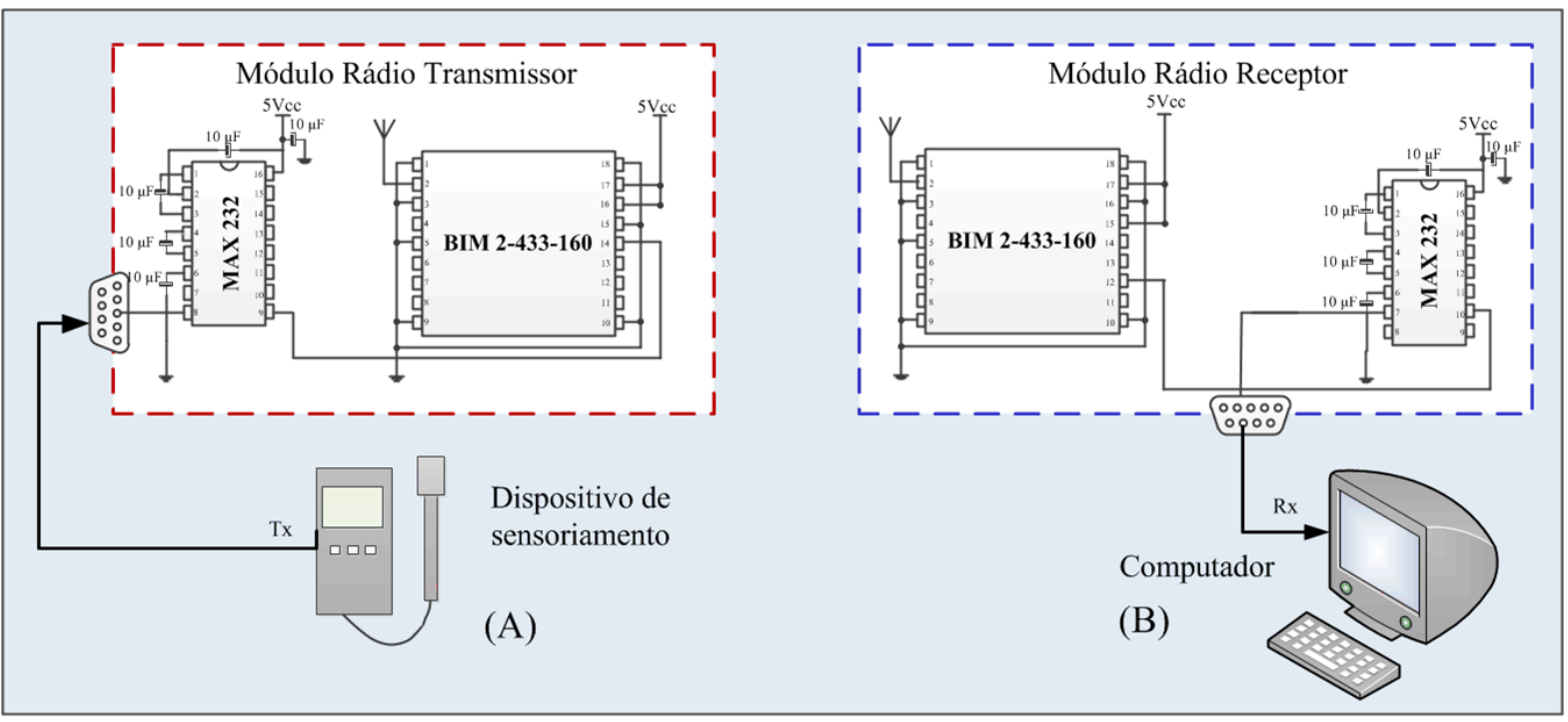

Figura 1: Esquema de montagem elétrica do módulo de rádio transmissão (A) e recepção (B). Os módulos de transmissão e recepção têm os mesmos componentes eletrônicos e a única diferença de montagem é um fio de conexão do dispositivo de rádio comunicação, modelo BIM2-433-160.

O módulo de rádio opera com um padrão elétrico chamado TTL que utiliza tensões de 0 e 5 Volts, enquanto os dispositivos de sensoriamento e o computador utilizam um padrão chamado RS-232 que utiliza -12 e +12 Volts. Assim, é necessário um circuito que faça o devido ajuste de níveis de tensão. Neste trabalho, esse ajuste é feito pelo componente MAX232, conforme mostra a Figura 1.

Para testes do sistema de telemetria montado, primeiro foram realizados testes em campo aberto para verificar o alcance da transmissão de dados e a taxa de erros que o mesmo apresentava. Posteriormente o termo-higrômetro foi utilizado para o monitoramento da temperatura do ar, no interior de uma casa de vegetação efetuando as análises das medições térmicas.

Neste trabalho desenvolveu-se um software recebe os dados e os gravam em um arquivo no disco do computador. Posteriormente, os dados gravados no arquivo podem ser utilizados para outros softwares de edição de texto ou de processamento estatístico. $\mathrm{O}$ nome do arquivo gerado pelo software é formado com a data e hora do sistema, relativo ao momento em que o arquivo foi criado, facilitando no momento de busca ou pesquisa do mesmo, esse processo impede que haja dois documentos com mesmo nome e isso impede que os arquivos sejam sobrepostos e os dados perdidos. 


\section{RESULTADOS E DISCUSSÃO}

A Figura 2 apresenta o circuito de hardware montado com os módulos de transmissão e recepção de dados desenvolvidos neste trabalho, observa-se que os módulos são de simples construção, sendo formados por apenas dois componentes eletrônicos ativos.

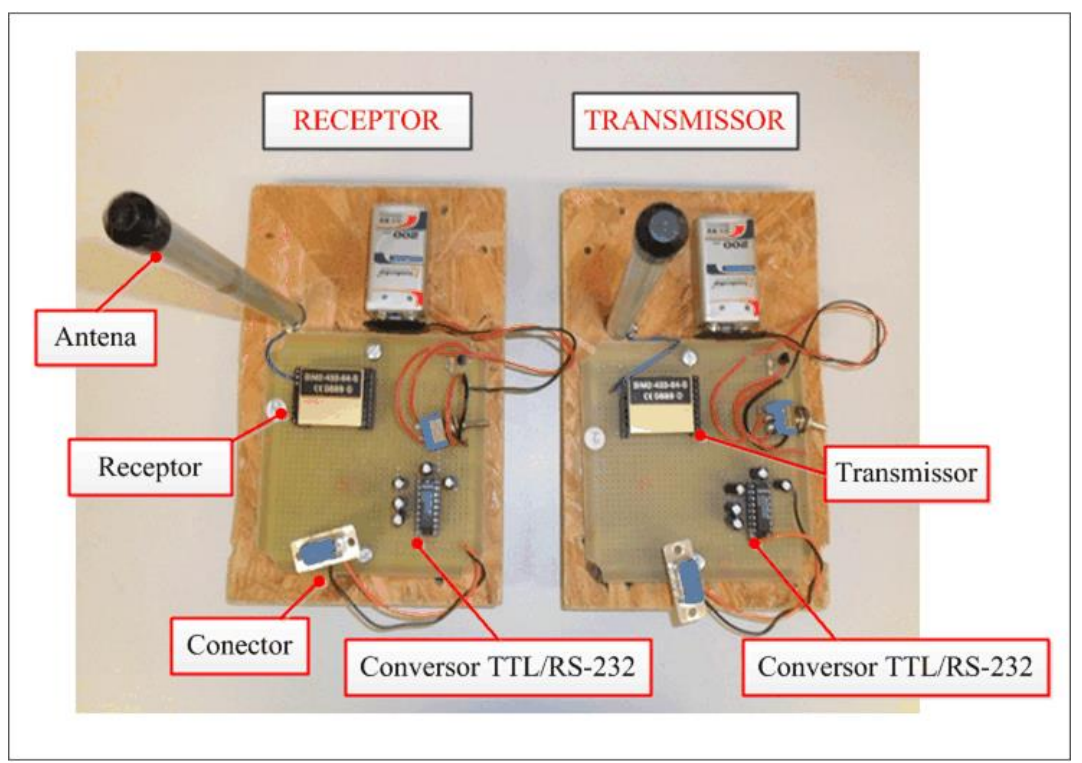

Figura 2: Protótipo dos módulos de rádio transmissão e comunicação, montados neste trabalho. A foto é a implantação real do circuito mostrado na Figura 1.

A Figura 3 mostra a tela principal do software de recepção de dados e os seus detalhes. No processo de operação do software o usuário deverá conectar $\mathrm{o}$ modulo receptor de dados via rádio à interface serial do computador, em seguida o usuário deve ativar a opção Serial para configurar a porta serial de acordo com as especificações do instrumento. Por exemplo, é necessária a configuração do Nome da porta, Baud rate (taxa de transmissão), Paridade, Data bits e Stop bits. Após configurar a porta, o usuário deve ativar opção Conexão para que a porta serial seja efetivamente ativada em termos de hardware, conforme mostra no menu na Figura 3 (D).

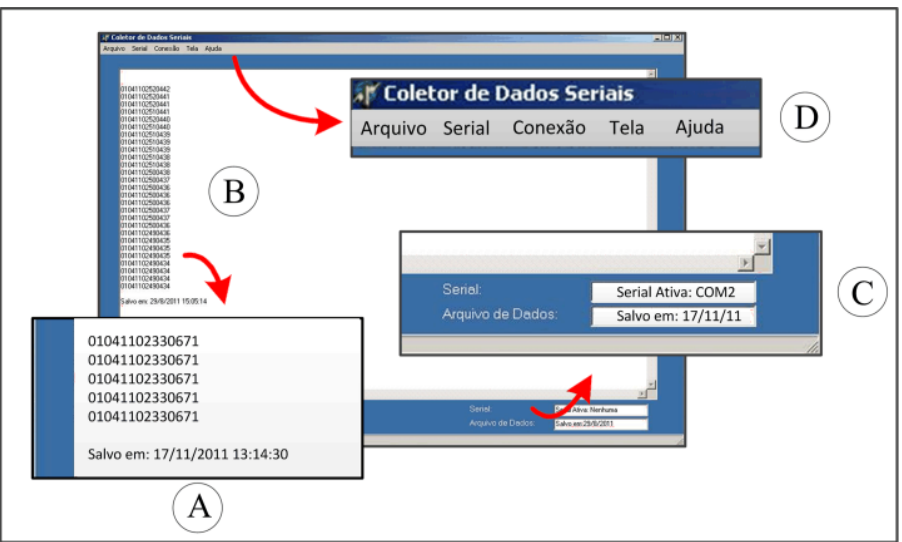

Figura 3: Tela principal do software de recepção de dados serial (B) e suas características de gravação de dados (A) apresentação de informações (C) e o menu de acesso (D). 
A partir do momento em que a conexão é estabelecida inicia-se o processo de recepção dos dados na janela de recepção dos dados, onde os mesmos são automaticamente mostrados em uma tela, conforme mostra os itens (A) e (B) na Figura 3. O item (C) da Figura 3 mostra a porta de comunicação que foi utilizada pelo usuário e o arquivo de dados que esta aberto no momento. Para gravar os dados o usuário acessa o menu Arquivo, onde encontra a opção Gravar Dados que permite que todas as informações recebidas pelo software e as que estejam sendo mostradas na tela do computador, também sejam gravadas em um arquivo no formato txt, conforme mostrado na Figura 3 (D).

Foi possível perceber que a distância máxima de transmissão de dados que foi de 120 metros, e que a partir disso o sinal de rádio frequência diminuía consideravelmente, provocando erro e comprometendo a recepção das informações. Esse erro é considerado normal em sistemas de rádio comunicação, visto que existem diversos fatores que podem interferir na onda eletromagnética e, consequentemente, provocando erros durante o processo de transmissão, como já constatado em trabalhos realizados por Arce (2008) e Monteiro (2007).

Foi realizado a implementação do sistema de telemetria em numa casa de vegetação. Neste caso o módulo transmissor de dados foi acoplado ao termo-higrômetro modelo HTR-152, utilizado para o monitoramento da temperatura do ar. O módulo, configurado como receptor foi conectado a um computador através da interface serial.

A Figura 4 mostra a forma com que foi instalado o módulo de transmissão de dados acoplado ao termo-higrômetro no interior da casa de vegetação. Nota-se que o módulo de sensoriamento composto pelo termo-higrômetro e dispositivo de sensoriamento pode ser facilmente realocado dentro da casa de vegetação oferecendo mobilidade ao dispositivo de sensoriamento.

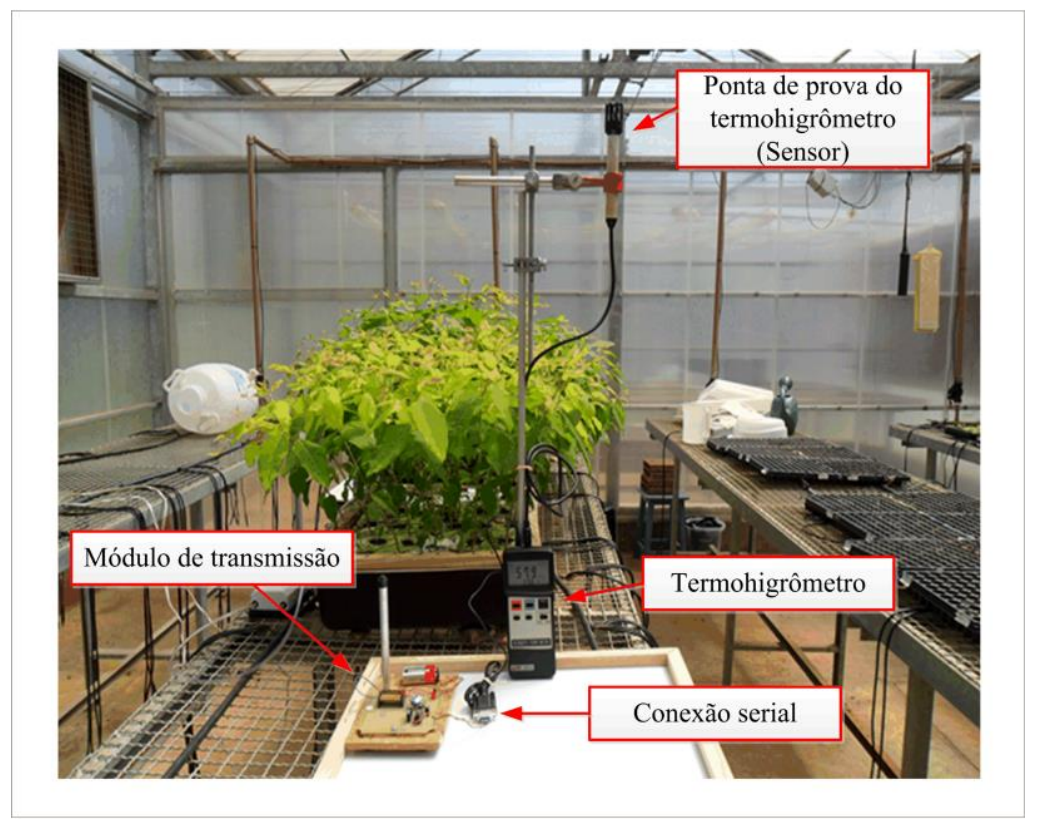

Figura 4: Forma de disposição do módulo de transmissão de dados acoplado ao termohigrômetro no interior de uma casa de vegetação, medindo a temperatura e a umidade relativa do ar em tempo real.

A Figura 5 mostra a variação da temperatura do ar $\left({ }^{\circ} \mathrm{C}\right)$ na casa de vegetação num período de 2 horas de coleta entre 9h:00min. às $11 \mathrm{~h}: 00 \mathrm{~min}$.
Foram realizadas 6000 medições consecutivas, com intervalo de tempo de 0,8 segundo entre cada uma delas. 


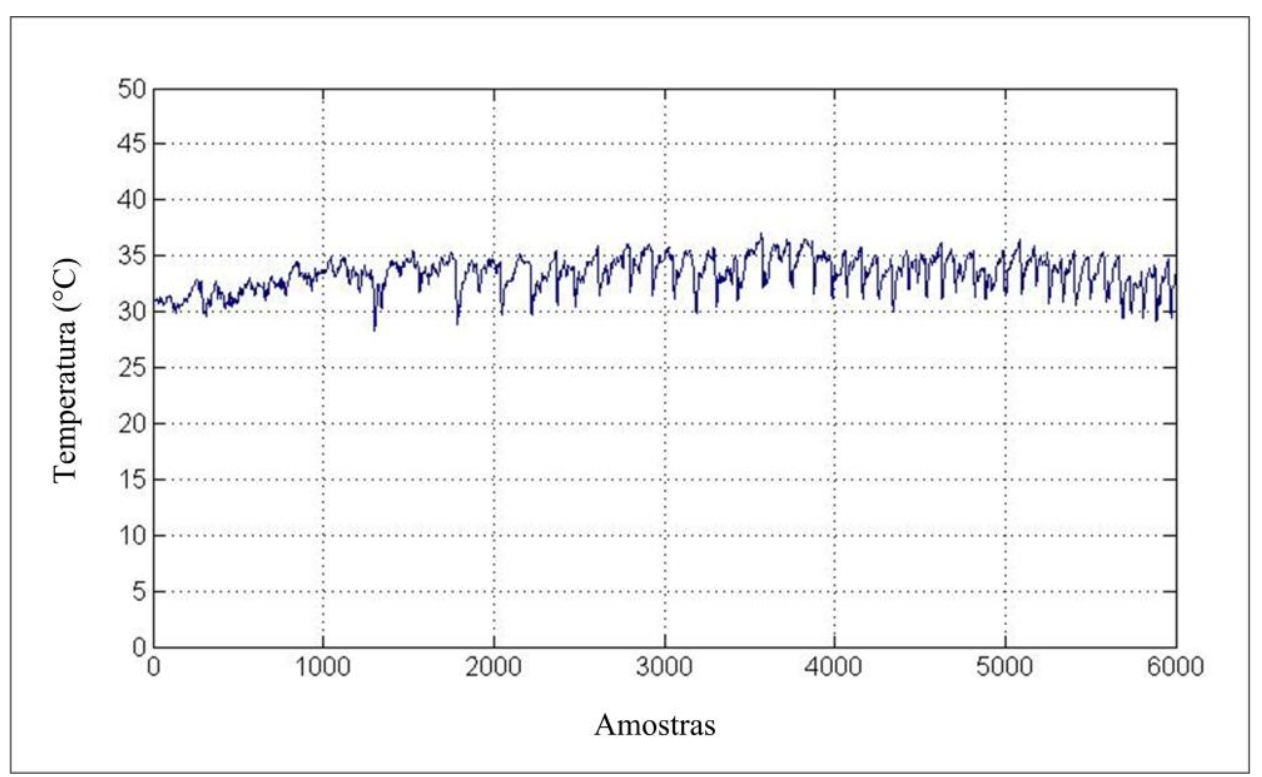

Figura 5: Dados de temperatura do ar $\left({ }^{\circ} \mathrm{C}\right)$ de testes com o sistema de telemetria realizado em casa de vegetação num período de 2 horas de coleta totalizando 6000 amostras térmicas.

Durante o período de medições, a temperatura oscilou na faixa entre $30 \mathrm{e}$ $35^{\circ} \mathrm{C}$. Esse comportamento se deve ao fato dos testes terem sido realizados em uma casa de vegetação com controle térmico, o qual ligava e desligava um sistema de ventilação a fim de manter a temperatura em determinado nível. Este comportamento foi relatado no trabalho realizado por Kittas e Bartzanas (2006) que comprova que o sistema de ventilação exerce grande influência no comportamento da temperatura do ar no interior de casas de vegetação, segundo seu estudo estas variações podem chegar até 2 ${ }^{\circ} \mathrm{C}$. O acionamento do sistema de

\section{CONCLUSÕES}

O sistema de telemetria desenvolvido com base no dispositivo, modelo BIM2-433-160, foi capaz de enviar os dados de medições térmicas a uma distância de 120 metros, sem erros de transmissão, o que assegura uma operação confiável e uma distância satisfatória para esse tipo de aplicação.

Cada dispositivo de rádio BIM2433-160 tem um consumo de energia de $17,5 \mathrm{~mA}$ operando como transmissor e $28,0 \mathrm{~mA}$ operando como receptor. Isso ventilação provoca uma rápida queda da temperatura e quando a mesma atinge determinado valor, o ventilador é automaticamente desligado, fazendo com que a temperatura aumente e tenda a voltar ao seu valor inicial, quando então o sistema de ventilação é novamente ativado. Esse tipo de ambiente foi intencionalmente escolhido por, apesar de manter a temperatura dentro de uma faixa específica de valores, prova variações bruscas dentro desta faixa e assim cria um ambiente menos estável, onde o sistema de medição e telemetria poderia ser analisado de forma mais crítica.

assegura ao módulo baixo custo de operação no tocante ao consumo de energia;

O módulo de telemetria desenvolvido pode ser conectado a qualquer dispositivo de sensoriamento ambiental que tenha uma saída de dados serial, no padrão RS232, o que é muito comum em modelos, comerciais de instrumentos. Isso assegura uma grande flexibilidade ao sistema de telemetria, para 
ser aplicado no monitoramento de diversos outros parâmetros físicos.

Em termos gerais, o trabalho atingiu o seu objetivo que era focado na aquisição de dados à distância em casas de vegetação, o que motivou o presente artigo.

\section{AGRADECIMENTOS}

Ao Conselho Nacional de Desenvolvimento Cientifico e Tecnológico - CNPq pela concessão da bolsa de estudos ao primeiro autor.

\section{REFERÊNCIAS}

ALMARAZ, J. R. M.; PACHECO, I. T.; GALVAN, C. D.; GONZALEZ, R. G. G.; MEDINA, L. M. C.; TRONCOSO, R. J.; GUILLEN, J. R. R. FPGA-based wireless smart sensor for real-time photosynthesis monitoring. Computers and Electronics in Agriculture, v.95, n.1, p.58-69, 2013.

ARAÚJO, E. C.; URIBE-OPAZO, M. A.; JOHANN, J. A. Modelo de regressão espacial para estimativa da produtividade da soja associada a variáveis agrometeorológicas na região oeste do Estado do Paraná. Engenharia Agrícola, Jaboticabal, v.34, n.2, p.286-299, mar./abr. 2014.

ARCE, A. I. C. Rede de sensores sem fio na coleta de dados fisiológicos de bovinos para aplicações na zootecnia de precisão. 2008. 86 f . Dissertação (Mestrado em Zootecnia)-Universidade de São Paulo, Pirassununga, 2008.

ARMINDO, R. A.; QUEIROZ, T. M.; BOTREL, T. A.; GARZELLA, T. C. Desenvolvimento e avaliação de um sistema de aquisição de dados para medição de vazão, "auto-venturi". Bioscience, Uberlândia, v. 27, n. 5, p. 764774, set./out. 2011.

BACK, A. J. Desempenho de métodos empíricos baseados na temperatura do ar para a estimativa da evapotranspiração de referência em Urussanga, SC. Irriga, Botucatu, v. 13, n. 4, p. 449-466, out./dez. 2008.

BAGSHAW, E. A.; LISHMAN, B.; WADHAM, J. L.; BOWDEN, J. A.; BURROW, S. G.; CLARE, L. R.; CHANDLER, D. Novel wireless sensors for in situ measurement of sub-ice hydrologic systems. Animals of Glaciology, v.55, n.65, p.41-50, 2014.

CARDEN, F.; JEDLICKA, R.; HENRY, R. Telemetry systems engineering. Norwood: Artech House, 2002. 558 p.

CASAS, O.; LÓPEZ, M.; QUÍLEZ, M.; FARRE, X. M.; HORNERO, G.; ROVIRA, C.; PINILLA, M. R.; RAMOS, P. M.; BORGES, B.; MARQUES, H.; GIRÃO, P. S. Wireless sensor network for smart composting monitoring and control, Measurement, v.47, n.1, p.483-495, 2014.

CLEAVER, K.; GANGULY, S. Shaping the future of water for agriculture: a sourcebook for investment in agricultural water management. Washington, DC: World Bank, 2005. 334 p.

FERRASA, M. Sistema de monitoramento de temperatura e umidade em silos graneleiros via rádio. 2008. 121 f. Tese (Doutorado em Agronomia/Energia na Agricultura)-Faculdade de Ciências Agronômicas, Universidade Estadual Paulista, Botucatu, 2008.

GOMES, D. P.; CARVALHO, D. F.; OLIVEIRA NETO, D. H.; SANTOS, C. A. B. Estimativa da temperatura do ar e da evapotranspiração de referência no Estado do Rio de Janeiro. Irriga, Botucatu, v.19, n.2, p.302-314, abr./jun. 2014.

KITTAS, C.; BARTZANAS, T. Greenhouse microclimate and dehumidification effectiveness under different ventilator configurations. Building and Environment, Oxford, v. 42, n. 1, p. 3774-3784, Jun. 2006.

MAJONE, B.; VIANI, F.; FILIPPI, E.; BELLIN, A.; MASSA, A.; TOLLER, G.; ROBOL, F.; SALUCCI, M. Wireless sensor network deployment for monitoring 
soil moisture dynamics at the field scale, Procedia environmental sciences, v.19, n.1, p. 426-435, 2013.

MONTEIRO, T. H. W.; SOUZA, W. L.; ALBUQUERQUE, H. A. P.; SILVA, P. H. F. Controle sem fio de uma esteira transportadora através de computador. In: CONGRESSO DE PESQUISA E INOVAÇÃO DA REDE NORTE NORDESTE DE EDUCAÇÃO TECNOLÓGICA, 2., 2007, João Pessoa. Anais... João Pessoa, 2007. 1 CD-ROM.

WEBSTER, J. G. The measurement, instrumentation and sensors handbook. Heidelberg: Springer, 1999. 156 p.

ZHANG, M.; LI, M.; WANG, W.; LIU, C.; GAO, H. Temporal and spatial variability of soil moisture based on WSN, Mathematical and computer modelling, v.58, n.1, p.826-833, 2013. 